\title{
Prevalence and Risk Factors of Hemodynamic Instability Associated with Preload-Dependence During Continuous Renal Replacement Therapy in a Prospective Observational Cohort of Critically III Patients
}

\author{
Guillaume CHAZOT \\ Hospices Civils de Lyon \\ Laurent BITKER \\ HOSPICES CIVILS DE LYON \\ Mehdi MEZIDI \\ Hospices Civils de Lyon \\ Nader CHEBIB \\ Hospices Civils de Lyon \\ Paul CHABERT \\ Hospices Civils de Lyon \\ Louis CHAUVELOT \\ Hospices Civils de Lyon \\ Laure FOLLIET \\ Hospices Civils de Lyon \\ Guillaume DAVID \\ Hospices Civils de Lyon \\ Judith PROVOOST \\ Hospices Civils de Lyon
}

Hodane YONIS

Hospices Civils de Lyon

Jean-christophe Richard ( $\nabla_{\text {j-christophe.richard@chu-lyon.fr ) }}$

Hôpital de la Croix-Rousse- Hospices Civils de Lyon https://orcid.org/0000-0003-1503-3035

\section{Research}

Keywords: Renal replacement therapy, acute circulatory failure, preload dependence, pulse contour, thermodilution, hemodynamic instability, acute kidney injury, net ultrafiltration rate 
Posted Date: December 29th, 2020

DOl: https://doi.org/10.21203/rs.3.rs-136892/v1

License: (c) (i) This work is licensed under a Creative Commons Attribution 4.0 International License. Read Full License 


\section{Abstract}

\section{Background}

Hemodynamic instability is a frequent complication of continuous renal replacement therapy (CRRT). Postural tests (i.e. passive leg raising in the supine position or Trendelenburg maneuver in the prone position) combined with measurement of cardiac output are highly reliable to identify preloaddependence and may provide new insights into the mechanisms involved in hemodynamic instability related to CRRT (HIRRT). We aimed to assess the prevalence and risk factors of HIRRT associated with preload-dependence in ICU patients.

\section{Methods}

We conducted a single-center prospective observational cohort study in ICU patients with acute kidney injury KDIGO 3, started on CRRT in the last 24 hours, and monitored with a PiCCO $®$ device. The primary endpoint was the rate of HIRRT episodes associated with preload-dependence during the first 7 days after inclusion. HIRRT was defined as the occurrence of a mean arterial pressure below $65 \mathrm{~mm} \mathrm{Hg}$ requiring therapeutic intervention. Preload-dependence was assessed by postural tests every 4 hours, and during each HIRRT episode. Data are expressed in median [1rst quartile-3rd quartile], unless stated otherwise.

\section{Results}

42 patients (62\% male, age 69 [59-77] year, SAPS-2 65 [49-76]) were included 6 [1-16] hours after CRRT initiation and studied continuously for 121 [60-147] hours. A median of 5 [3-8] HIRRT episodes occurred per patient, for a pooled total of 243 episodes. 131 episodes (54\% [ $\left.\mathrm{Cl}_{95 \%}: 48 \%-60 \%\right]$ ) were associated with preload-dependence, 108 (44\%, [ $\left.\mathrm{Cl}_{95 \%}: 38 \%-51 \%\right]$ ) without preload-dependence, and 4 were unclassified. Multivariate analysis (using variables collected prior to HIRRT) identified the following variables as risk factors for the occurrence of HIRRT associated with preload-dependence: preload-dependence before HIRRT (odd ratio $(O R)=3.82, p<0.001)$, delay since last HIRRT episode $>8$ hours $(O R=0.56, p<0.05)$, lactate $\left(O R=1.21\right.$ per $1-\mathrm{mmol} . \mathrm{L}^{-1}$ increase, $\left.\mathrm{p}<0.05\right)$, cardiac index $\left(\mathrm{OR}=0.47\right.$ per $1-\mathrm{L} \cdot \mathrm{min}^{-1} \cdot \mathrm{m}^{-2}$ increase, $p<0.001)$ and SOFA at ICU admission (OR $=0.91$ per 1-point increase, $p<0.001)$. None of the CRRT settings was identified as risk factor for HIRRT.

\section{Conclusions:}

In this single center study, HIRRT associated with preload-dependence was slightly more frequent than HIRRT without preload-dependence in ICU patients undergoing CRRT. Testing for preload-dependence to adjust fluid removal by CRRT could help preventing HIRRT occurrence during CRRT.

\section{Background}

Acute kidney injury (AKI) is independently associated with morbidity and mortality in critically ill patients [1]. A positive fluid balance during AKI is independently associated with mortality in observational studies 
$[2,3]$, suggesting that optimizing net ultrafiltration rate to control fluid balance may improve AKI mortality. However, hemodynamic instability related to renal replacement therapy (HIRRT) may be related to excessive fluid removal and may also impair mortality and renal recovery [4-6]. In hemodynamically unstable patients, continuous renal replacement therapy (CRRT) is the preferred modality since it may be associated with better hemodynamic tolerance [7-9]. In clinical practice, the consequence of HIRRT occurrence is often a discontinuation of the net ultrafiltration rate, while the underlying mechanism of HIRRT may be unrelated to fluid removal. Indeed, HIRRT may be related to the underlying cause of AKI, to cardiac output decrease of various origins (hypovolemia, hypocalcemia, diastolic dysfunction...) or to alterations of the vasomotor tone related to membrane/circuit bio-incompatibility, ultrafiltrate/dialysate temperature or ionic imbalance, among others [10].

We previously showed that most of HIRRT episodes occurring during intermittent hemodialysis are unrelated to preload dependence (i.e. cardiac output increase in response to fluid administration), and should not necessarily lead to reduction of fluid removal by hemodialysis [11]. To our knowledge, there is no published study reporting the prevalence of HIRRT associated with preload-dependence under CRRT. Since postural tests (i.e. passive leg raising (PLR) in the supine position or Trendelenburg maneuver in the prone position) combined to continuous measurement of cardiac output are highly reliable to identify preload dependence $[12,13]$, we hypothesized that their implementation in CRRT monitoring may provide new insights into the mechanisms involved in HIRRT.

\section{Methods}

\section{Study aim}

The aim of this study was to assess prevalence and risk factors of HIRRT associated with preloaddependence during the first 7 days of CRRT.

\section{Study design and setting}

We conducted a prospective, observational, single-center cohort study between May 9, 2017 and September 1st, 2020 in a 15-bed medical intensive care unit (ICU). The study was approved by an ethics committee (CPP lle de France IV, ID-RCB 2017-A00483-50) and was registered on ClinicalTrials.gov (NCT 03139123) on May 2nd, 2017. Informed consent for study inclusion was obtained from all individual participants and/or their closest relatives.

\section{Patients}

To be eligible, the subjects had to fulfill all the following inclusion criteria: aged 18 years or older, with acute kidney injury KDIGO 3 [14], treated with CRRT for less than 24 hours and monitored by mean of a PiCCO ${ }^{\circledR}$ device (Pulsion Medical Systems, Feldkirchen, GERMANY) mandated by acute circulatory failure. Exclusion criteria were pregnancy, lower limb amputation, intracranial hypertension, known obstruction of inferior vena cava, ongoing directives to withhold or withdraw life sustaining treatment, lack of consent 
by patient or next of kin, lack of affiliation to social security, patient under a legal protective measure, inclusion in another research study and previous inclusion in current study.

\section{Data collection}

The following variables were recorded at inclusion: demographic and anthropometric data, time of ICU admission and inclusion, admission category, simplified acute physiology score (SAPS) II [15], and reason for PiCCO $\circledast$ monitoring.

The following variables were recorded at inclusion, every 4 hours and at the onset of each HIRRT episode until study completion: heart rate, systolic, diastolic and mean arterial pressures, pulse pressure variation (PPV), central venous pressure, cardiac index assessed by both thermodilution and pulse contour analysis, stroke volume variation (SVV), extravascular lung water index, global end-diastolic volume index, pulmonary vascular permeability index, global ejection fraction, vasopressor administration and dose, inotrope administration, mechanical ventilation use, CRRT settings (blood flow, ultrafiltrate or dialysate rate and temperature, net ultrafiltration rate), and preload dependency tested as described below.

The following variables were recorded at inclusion and daily until study completion: Sequential Organ Failure Assessment (SOFA) score [16], body weight, fluid balance, arterial blood gas, arterial lactate, hemoglobin, fulfilment of sepsis and septic shock criteria [17].

Missing data per variable are reported in additional file 1.

\section{Study follow up}

Patients were followed during the first seven days after inclusion or less in case of occurrence of any of the following events: death, end of life care, CRRT cessation or interruption of PiCCO ${ }^{\circledR}$ monitoring.

\section{CRRT management}

The indication, technique (continuous veno-venous hemofiltration (CVVH) or continuous veno-venous hemodialysis (CVVHD)) and settings of CRRT were under the responsibility of the clinician in charge of the patients, in accordance with current practice guidelines [14]. CRRT was performed with the Multifiltrate ${ }^{\circledR}$ station and the Ultraflux ${ }^{\circledR}$ AV1000S hemofilter (Fresenius Medical Care, Bad Homburg, GERMANY). CRRT settings were adjusted by the attending physician.

\section{Hemodynamic measurements}

HIRRT was defined as mean arterial pressure below $65 \mathrm{~mm} \mathrm{Hg}$ justifying any therapeutic intervention among the following ones: fluid administration, initiation or increase in vasopressor dose, or discontinuation or decrease of net ultrafiltration rate on CRRT. Once hypotension occurred and before any therapeutic intervention, a postural test (PLR in the supine position or Trendelenburg maneuver in the prone position) was performed during 1 minute to assess for preload dependence. PLR was performed from the semi-recumbent position with the trunk at $45^{\circ}[18]$ and the Trendelenburg maneuver was 
performed from a $13^{\circ}$ upward bed angulation to a $-13^{\circ}$ downward bed angulation in patients in the prone position [13]. Preload dependence was deemed present if the pulse contour-derived cardiac index increased by at least $10 \%$ and $8 \%$ during the PLR test and the Trendelenburg maneuver, respectively.

Therapeutic management of HIRRT was at the discretion of the clinician in charge of the patient and was not protocolized. A 1-hour period without new hemodynamic assessment was allowed after each HIRRT episode onset to wait for treatment effect.

Hemodynamic measurements including a postural test were systematically performed by trained ICU nurses every four hours and during each HIRRT episode. Regular training sessions of nurses to hemodynamic measurements were organized to ensure quality of data acquisition. Arterial and central venous blood pressures were continuously monitored, using arterial femoral and jugular vein catheters, respectively, connected to an Intellivue MP40 monitor equipped with the PiCCO ${ }^{8}$ technology module (Philips Healthcare, Andover, MA, USA). Cardiac output was assessed using the PiCCO ${ }^{\circledR}$ device, calibrated with the transpulmonary thermodilution technique at least every 4 hours, using a triplicate intravenous infusion of $15 \mathrm{~mL}$ cold serum saline. Cardiac output was then continuously monitored using pulse contour analysis with the PiCCO ${ }^{\circ}$ device. Arterial dynamic elastance was computed as the ratio of PPV over SVV.

\section{End points}

Primary end point was the rate of HIRRT associated with preload-dependence, with reference to the total number of HIRRT episodes occurring during the first seven days after inclusion. Secondary end point was the identification of risk factors for HIRRT associated with preload-dependence.

\section{Statistical analysis}

Statistical analyses were performed using R software version 4.0.2 [19] and the following packages: Ime4 [20], Lmertest [21], pROC [22], PropCls [23], MultinomialCI [24] and mice [25]. A p value below 0.05 was chosen for statistical significance. The statistical unit was the hemodynamic measurement. Power of the study was computed using the normal approximation confidence interval method [26]. Assuming a rate of HIRRT associated with preload-dependence between 0.25 and 0.5 , we calculated that with a sample size between 72 and 96 HIRRT episodes, the study would provide at worst a $\pm 10 \%$ precision in the $95 \%$ confidence interval of the prevalence of HIRRT associated with preload-dependence. We decided to include conservatively at least 100 HIRRT episodes and at least 50 patients to ensure minimal representativity. Analyses were performed on all included patients, including those prematurely withdrawn. Medians and interquartile ranges were reported for continuous variables and counts in each category with corresponding percentages were reported for categorical variables. Ninety-five percent confidence intervals $\left(\mathrm{Cl}_{95 \%}\right)$ for multinomial proportions were computed using the Sison and Glaz method [27]. A logistic regression mixed model was used to assess whether each therapeutic intervention differed between preload-dependent and preload-independent HIRRT episodes, and the Bonferroni correction was used to account for multiple testing. To test which variables could predict occurrence of HIRRT associated with preload-dependence, the whole dataset was restricted to hemodynamic measurements 
obtained without HIRRT, and a new variable was computed (occurrence of HIRRT associated with preloaddependence in the subsequent measurement (Yes/No)). Variables were entered into a mixed logistic regression model, using patient as variable with a random effect, and occurrence of HIRRT associated with preload-dependence in the subsequent measurement as the dependent variable. Some continuous variables were entered in the model as dichotomized variables, using ROC curve analysis and computation of optimal cut-off points by maximizing the Youden index. Independent variables associated with occurrence of HIRRT with preload-dependence with a p value below 0.2 in univariate analysis were selected for inclusion in a multivariable mixed logistic regression model, using backward stepwise descending selection. Interactions between predictors were assessed on the final model. Missing data in multivariate analyses were handled using multiple imputations and predictive mean matching. Model calibration was assessed by the Hosmer-Lemeshow test and model discrimination by the C-statistic.

\section{Results}

\section{Screening}

During the study period, 331 patients underwent CRRT and 42 were included. Reasons for non-inclusion are listed in Fig. 1.

\section{Population characteristics at inclusion (Table 1)}


Table 1

Demographic data at inclusion.

\section{Variables}

Age (year)

Male gender

Admission category

- medical

- urgent surgery

SAPS 2 at ICU admission

Time between ICU admission and CRRT onset

Time between CRRT onset and inclusion (hr)

BMI at ICU admission $\left(\mathrm{kg} \cdot \mathrm{m}^{-2}\right)$

Comorbidities

- diabetes

- CRF

$\cdot \mathrm{CHF}$

- coronary disease

- cirrhosis

Sepsis *

Septic shock *

SOFA score

Mechanical ventilation

Vasopressor administration

Dobutamine administration

Cumulative fluid balance from ICU admission $(\mathrm{kg})$

$\mathrm{BMI}=$ body mass index; $\mathrm{CHF}$ = chronic heart failure; $\mathrm{CRF}$ = chronic respiratory failure; $\mathrm{CRRT}=$ continuous renal replacement therapy; ICU = intensive care unit; IQR = interquartile range; SAPS $2=$ simplified Acute Physiology Score 2; SOFA = sequential Organ Failure Assessment.

* According to sepsis 3 criteria.

Enrolment stopped prematurely after inclusion of 42 patients since nurse staff overwork related to the COVID-19 pandemics hindered inclusions, and since the required number of HIRRT episodes had been

\section{Median [IQR] or count (\%)}

$69[59-77]$

$26(62 \%)$

$41(98 \%)$

$1(2 \%)$

65 [49-76]

36 [8-73]

$6[1-16]$

26 [22-31]

$12(29 \%)$

$4(10 \%)$

$10(24 \%)$

$12(29 \%)$

$6(14 \%)$

$33(79 \%)$

$24(57 \%)$

14 [12-16]

$35(83 \%)$

40 (95\%)

$6(14 \%)$

$2[0-6]$ 
substantially exceeded. Forty-two patients (62\% male) with median age 69 [59-77] years were included 6 [1-16] hours after CRRT onset. At inclusion, 35 patients (83\%) underwent mechanical ventilation, 33 (79\%) fulfilled sepsis criteria and 24 (57\%) fulfilled septic shock criteria [17]. The cumulative fluid balance between admission and inclusion was $2[0-6] \mathrm{kg}$.

\section{Hemodynamic data and CRRT settings at inclusion (Table 2)}


Table 2

Hemodynamic data and CRRT settings at inclusion.

\begin{tabular}{|c|c|}
\hline Variables & Median [IQR] or count (\%) \\
\hline Vasopressor dose $\left(\mu \mathrm{g} \cdot \mathrm{kg}^{-1} \cdot \mathrm{min}^{-1}\right)$ & $0.54[0.21-1.41]$ \\
\hline Arterial lactate $\left(\mathrm{mmol} . \mathrm{L}^{-1}\right)$ & $2.9[1.5-5.0]$ \\
\hline Heart rate $\left(\min ^{-1}\right)$ & $96[74-113]$ \\
\hline MAP (mm Hg) & $70[62-75]$ \\
\hline CVP $(\mathrm{mm} \mathrm{Hg})$ & $8[6-10]$ \\
\hline $\mathrm{Cl}_{\mathrm{TD}}\left(\mathrm{L} \cdot \mathrm{min}^{-1} \cdot \mathrm{m}^{-2}\right)$ & $2.8[2.1-3.3]$ \\
\hline $\mathrm{Cl}_{\mathrm{PC}}\left(\mathrm{L} \cdot \mathrm{min}^{-1} \cdot \mathrm{m}^{-2}\right)$ & $2.6[2.1-3.2]$ \\
\hline ISVR (dynes.sec.cm ${ }^{-5}$ ) & $1757[1277-2224]$ \\
\hline EVLWI (ml. $\left.\mathrm{kg}^{-1} \mathrm{PBW}\right)$ & $11.5[8.9-15.2]$ \\
\hline PVPI & $2.2[1.9-3.0]$ \\
\hline GEDVI (mL.m²) & $665[593-843]$ \\
\hline GEF (\%) & 18 [14-24] \\
\hline PPV (\%) & $9[5-14]$ \\
\hline SVV (\%) & $13[7-20]$ \\
\hline $\mathrm{Ea}_{\mathrm{dyn}}$ & $0.8[0.6-1.0]$ \\
\hline Preload dependence assessed by postural test & $22(52 \%)$ \\
\hline Type of CRRT & $39(93 \%)$ \\
\hline$\cdot \mathrm{CVVH}$ & $3(7 \%)$ \\
\hline - CVVHD & \\
\hline
\end{tabular}

CRRT = continuous renal replacement therapy; $\mathrm{Cl}_{\mathrm{PC}}=$ cardiac index assessed by pulse contour analysis; $\mathrm{Cl}_{\mathrm{TD}}=$ cardiac index assessed by thermodilution; $\mathrm{CVP}=$ central venous pressure; $\mathrm{CVVH}=$ continuous veno-venous hemofiltration; CVVHD = continuous veno-venous hemodialysis; $\mathrm{Ea}_{\mathrm{dyn}}=$ dynamic arterial elastance; EVLWI = extravascular lung water index; GEDVI = global end-diastolic volume index; GEF = global ejection fraction; IQR = interquartile range; ISVR = indexed systemic vascular resistance; MAP = mean Arterial Pressure; PBW = predicted body weight; $\mathrm{PPV}=$ pulse pressure variation; $\mathrm{PVPI}=$ pulmonary vascular permeability index; SVV = stroke volume variation.

* in patients treated with CVVH; ** in patients treated with CVVHD. 


\begin{tabular}{|c|c|}
\hline Variables & Median [IQR] or count (\%) \\
\hline Ultrafiltration rate $\left(\mathrm{ml} . \mathrm{kg}^{-1} \cdot \mathrm{hr}^{-1}\right)$ * & $26[24-31]$ \\
\hline Dialysate rate $\left(\mathrm{ml}^{\prime} \mathrm{kg}^{-1} \cdot \mathrm{hr}^{-1}\right) \star \star *$ & 23 [16-27] \\
\hline CRRT blood flow (ml.min $\left.{ }^{-1}\right)$ & $250[200-250]$ \\
\hline Net ultrafiltration rate $\left(\mathrm{ml} \cdot \mathrm{kg}^{-1} \cdot \mathrm{hr}^{-1}\right)$ & 0 [0-2.7] \\
\hline Ultrafiltrate/dialysate temperature $\left({ }^{\circ} \mathrm{C}\right)$ & 38 [37-39] \\
\hline \multicolumn{2}{|l|}{ CRRT circuit anticoagulation } \\
\hline • Heparin & $39(93 \%)$ \\
\hline - Citrate & $3(7 \%)$ \\
\hline \multicolumn{2}{|c|}{ 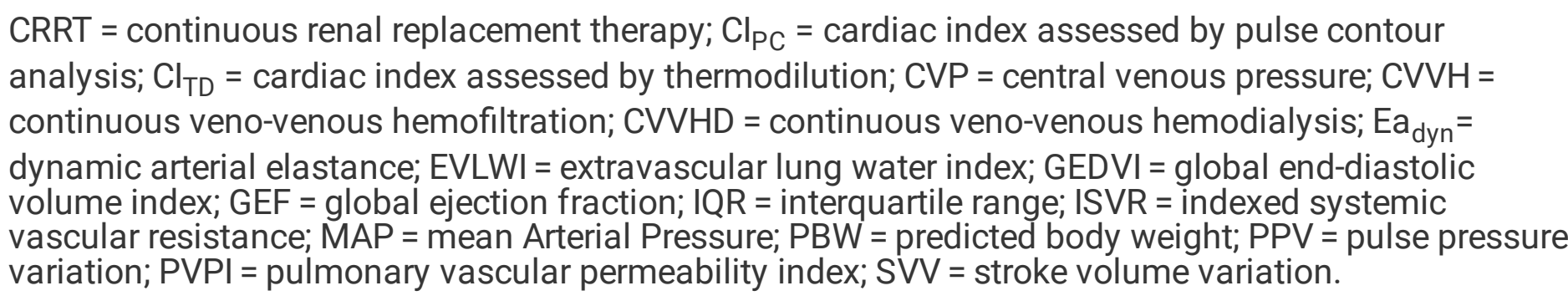 } \\
\hline * in patients treated with $\mathrm{CVVH} ; * \star$ in pa & \\
\hline
\end{tabular}

Forty patients (95\%) were under vasopressors with a median dose of $0.54[0.21-1.41] \mu \mathrm{g}^{\mathrm{kg}} \mathrm{kg}^{-1} \cdot \mathrm{min}^{-1}$, and preload-dependence was identified in $22(52 \%)$ patients. Thirty-nine patients $(93 \%)$ underwent CVVH and $3(7 \%)$ were treated by CVVHD. Net ultrafiltration rate amounted to $0[0-2.7] \mathrm{ml}^{-\mathrm{kg}^{-1}} \cdot \mathrm{hr}^{-1}$ at this time point.

\section{Hemodynamic data and CRRT settings during the study (Table 3)}


Table 3

Hemodynamic evaluations and CRRT settings during study.

\section{Variables}

Number of hemodynamic evaluations

Number of hemodynamic evaluations per patient

Study duration (hr)

Vasopressor dose $\left(\mu \mathrm{g} \cdot \mathrm{kg}^{-1} \cdot \mathrm{min}^{-1}\right)$

Vasopressor administration (\%)

Dobutamine administration (\%)

Arterial lactate $\left(\mathrm{mmol}^{\mathrm{L}} \mathrm{L}^{-1}\right)$

Heart rate $\left(\min ^{-1}\right)$

MAP $(\mathrm{mm} \mathrm{Hg})$

CVP $(\mathrm{mm} \mathrm{Hg})$

$\mathrm{Cl}_{\mathrm{TD}}\left(\mathrm{L} \cdot \mathrm{min}^{-1} \cdot \mathrm{m}^{-2}\right)$

$\mathrm{Cl}_{\mathrm{PC}}\left(\mathrm{L} \cdot \mathrm{min}^{-1} \cdot \mathrm{m}^{-2}\right)$

ISVR (dynes.sec.cm ${ }^{-5}$ )

EVLWI (ml.kg-1 PBW)

PVPI

GEDVI ( $\left.\mathrm{mL} \cdot \mathrm{m}^{-2}\right)$

GEF (\%)

PPV (\%)

SVV (\%)
Median [IQR] or count (\%)

1237

33 [19-41]

121 [60-147]

$0.29[0.08-0.81]$

$1042(85 \%)$

$91(7 \%)$

$1.8[1.4-2.9]$

94 [78-110]

73 [64-81]

7 [4-10]

$3.0[2.5-3.5]$

$2.9[2.4-3.5]$

1780 [1507-2095]

$10.5[8.7-13.3]$

$2.1[1.8-2.5]$

652 [582-811]

20 [16-23]

9 [5-15]

11 [7-18]

$\mathrm{Cl}_{\mathrm{PC}}=$ continuous cardiac index assessed by pulsed contour analysis; $\mathrm{Cl}_{\mathrm{TD}}=$ cardiac index assessed by thermodilution; $C R R T$ = continuous renal replacement therapy; $C V P=$ central venous pressure; $\mathrm{CVVH}=$ continuous veno-venous hemofiltration; CVVHD = continuous veno-venous hemodialysis; $\mathrm{Ea}_{\mathrm{dyn}}=$ dynamic arterial elastance; $\mathrm{EVLWI}=$ extravascular lung water index; GEDVI = global enddiastolic volume index; $\mathrm{GEF}$ = global ejection fraction; IQR = interquartile range; $M A P=$ mean arterial pressure; ISVR = indexed systemic vascular resistance; PBW = predicted body weight; $\mathrm{PVPI}$ = pulmonary vascular permeability index; $\mathrm{PPV}=$ pulse pressure variation; $\mathrm{PVPI}=$ pulmonary vascular permeability index; SVV = stroke volume variation.

* in patients treated with $\mathrm{CVVH}$; ** in patients treated with CVVHD. 


\begin{tabular}{|c|c|}
\hline Variables & Median [IQR] or count (\%) \\
\hline $\mathrm{Ea}_{\mathrm{dyn}}$ & $0.8[0.7-1.0]$ \\
\hline Preload dependence assessed by postural test & $490(41 \%)$ \\
\hline Type of CRRT & $1072(87 \%)$ \\
\hline$\cdot \mathrm{CVVH}$ & $165(13 \%)$ \\
\hline \multicolumn{2}{|l|}{$\cdot$ CVVHD } \\
\hline Ultrafiltration rate $\left(\mathrm{ml} \cdot \mathrm{kg}^{-1} \cdot \mathrm{hr}^{-1}\right)$ * & $27[24-31]$ \\
\hline Dialysate rate $\left(\mathrm{ml} \cdot \mathrm{kg}^{-1} \cdot \mathrm{hr}^{-1}\right)$ ** & $25[23-27]$ \\
\hline CRRT blood flow (ml.min $\left.{ }^{-1}\right)$ & $250[200-250]$ \\
\hline Net ultrafiltration rate $\left(\mathrm{ml} . \mathrm{kg}^{-1} \cdot \mathrm{h}^{-1}\right)$ & $1.4[0-2.9]$ \\
\hline Ultrafiltrate/dialysate temperature $\left({ }^{\circ} \mathrm{C}\right)$ & 38 [37-39] \\
\hline CRRT circuit anticoagulation & $946(77 \%)$ \\
\hline Heparin & 165 (13\%) \\
\hline Citrate & $126(10 \%)$ \\
\hline \multicolumn{2}{|l|}{ None } \\
\hline \multicolumn{2}{|c|}{$\begin{array}{l}\mathrm{Cl}_{\mathrm{PC}}=\text { continuous cardiac index assessed by pulsed contour analysis; } \mathrm{Cl}_{\mathrm{TD}}=\text { cardiac index assessed } \\
\text { by thermodilution; } \mathrm{CRRT}=\text { continuous renal replacement therapy; } \mathrm{CVP}=\text { central venous pressure; } \\
\mathrm{CVVH}=\text { continuous veno-venous hemofiltration; } \mathrm{CVVHD}=\text { continuous veno-venous hemodialysis; } \\
\mathrm{Ea}_{\text {dyn }}=\text { dynamic arterial elastance; } \mathrm{EVLWI}=\text { extravascular lung water index; } \mathrm{GEDVI}=\text { global end- } \\
\text { diastolic volume index; } \mathrm{GEF}=\text { global ejection fraction; } \mathrm{IQR}=\text { interquartile range; } \mathrm{MAP}=\text { mean arterial } \\
\text { pressure; ISVR = indexed systemic vascular resistance; } \mathrm{PBW}=\text { predicted body weight; } \mathrm{PVPI}= \\
\text { pulmonary vascular permeability index; } \mathrm{PPV}=\text { pulse pressure variation; } \mathrm{PVPI}=\text { pulmonary vascular } \\
\text { permeability index; } \mathrm{SVV}=\text { stroke volume variation. }\end{array}$} \\
\hline
\end{tabular}

Patients were followed during 121 [60-147] hours with 33 [19-41] hemodynamic evaluations per patient for a total of 1237 hemodynamic evaluations. 28 (67\%) patients were prematurely withdrawn from the study (15 due to CRRT cessation, 4 to end of life withdrawal of care, 8 to death before end of study, and 1 to interruption of $\mathrm{PiCCO}{ }^{\circledR}$ monitoring).

During the study, vasopressor dose was $0.29[0.08-0.81] \mu \mathrm{g} \cdot \mathrm{kg}^{-1} \cdot \mathrm{min}^{-1}$, arterial lactate was 1.8 [1.4-2.9] mmol.L ${ }^{-1}$. Preload-dependence was present in $41 \%$ of the hemodynamic evaluations. CRRT modality was CVVH or CVVHD during $87 \%$ and $13 \%$ of the hemodynamic evaluations, respectively. Ultrafiltration rate was 27 [24-31] ml. $\mathrm{kg}^{-1} . \mathrm{hr}^{-1}$ in CVVH-treated patients, dialysate rate was 25 [23-27] $\mathrm{ml}^{-\mathrm{hr}^{-1}}$ in CVVHD-treated patients, and net ultrafiltration rate was $1.4[0-2.9] \mathrm{ml} . \mathrm{kg}^{-1} . \mathrm{hr}^{-1}$. 


\section{HIRRT episodes}

Five [3-8] HIRRT episodes occurred per patient, for a pooled total of 243 episodes. Forty patients (98\%) experienced at least 1 episode of HIRRT, with most patients experiencing both preload-dependent and preload-independent HIRRT episodes (Fig. 2). One hundred thirty-one HIRRT episodes ( $54 \%{ }^{2} \mathrm{Cl}_{95 \%}$ : $48-$ $60 \%])$ were associated with preload-dependence, $108\left(44 \%\right.$, [ $\left.\left.\mathrm{Cl}_{95 \%}: 38-51 \%\right]\right)$ had no preload-dependence and 4 were unclassified since postural tests were not assessed. Therapeutic management of HIRRT episodes differed between, preload and non-preload dependent HIRRT episodes (Fig. 3). Vasopressors were significantly more used in HIRRT episodes without preload-dependence while the opposite was true for fluid administration. The delay between the last preceding hemodynamic measurement and HIRRT episode associated with preload-dependence was 104 [61-189] min.

\section{Risk factors for HIRRT associated with preload-dependence (Fig. 4)}

Univariate analysis of variables collected before HIRRT onset as predictors for occurrence of HIRRT associated with preload-dependence is presented in additional file 2. Multivariate analysis identified the following independent risk factors for occurrence of HIRRT associated with preload-dependence: preloaddependence before HIRRT (odd ratio $(\mathrm{OR})=3.82$ [2.30-6.36], $\mathrm{p}<0.001)$, arterial lactate level $(\mathrm{OR}=1.21$ [1.07-1.37] per 1 mmol.L ${ }^{-1}$ increase, $\left.p<0.05\right)$, delay since last HIRRT episode of at least 8 hours $(O R=$ 0.56 [0.34-0.94], $\mathrm{p}<0.05)$, cardiac index assessed by thermodilution before HIRRT (OR $=0.47$ [0.32-0.68] per $1 \mathrm{~L} \cdot \mathrm{min}^{-1} \cdot \mathrm{m}^{-2}$ increase, $\left.\mathrm{p}<0.001\right)$ and SOFA score at ICU admission $(\mathrm{OR}=0.91[0.86-0.96]$ per 1 point increase, $p<0.001)$.

\section{Discussion}

The main findings of the study are the following: 1- HIRRT associated with preload-dependence in patients under CRRT is slightly more frequent than HIRRT without preload-dependence; 2- HIRRT during CRRT is not independently related to CRRT settings in a selected population under invasive continuous hemodynamic monitoring, and is mainly related to underlying cardiovascular dysfunction; 3- preloaddependence is a risk factor for HIRRT associated with preload-dependence during CRRT and monitoring preload-dependence may be useful to adjust net ultrafiltration rate and prevent hemodynamic impairment in ICU patients under CRRT.

To our knowledge, there is no other published study reporting the prevalence of HIRRT associated with preload-dependence during CRRT. We report, with a high granularity of data and over a prolonged period of time, a rate of HIRRT associated with preload dependence close to $50 \%$, i.e. similar to the rate of preload-dependence during acute circulatory failure $[12,28]$. This result suggests that the systematic cessation or reduction of net ultrafiltration rate is not an adequate therapeutic option when facing an HIRRT episode under CRRT. In keeping with this finding, we previously reported that preload-dependence 
was only present in $19 \%$ of HIRRT episodes during intermittent hemodialysis in ICU [11]. Schortgen et al also reported that HIRRT frequently occurred early during intermittent hemodialysis sessions, prior to the removal of a significant fluid volume via ultrafiltration [29]. These elements emphasize the importance of considering other factors than hypovolemia when facing the life-threatening issue of HIRRT.

Prevalence of HIRRT ranged from 19 to $43 \%$ of CRRT treatments in previous observational studies [7, 9, 30]. The variability in the reported frequencies is partly attributable to the lack of a consensus definition of HIRRT. Indeed, Uchino et al defined HIRRT as a decrease of more than $20 \mathrm{mmHg}$ of systolic blood pressure or any increase of vasopressors whereas Akhoundi et al defined HIRRT as a new/sudden decrease of systolic blood pressure $>40 \mathrm{~mm} \mathrm{Hg}$, a mean arterial pressure of $<60 \mathrm{~mm} \mathrm{Hg}$, or a systolic blood pressure $<90 \mathrm{~mm} \mathrm{Hg}$, or any initiation or increased dose of vasoactive drugs, or the need for intravenous fluid boluses. In these studies, neither etiology nor mechanisms of HIRRT were investigated and the prevalence of HIRRT associated with preload-dependence was not studied.

However, although the main mechanisms of HIRRT are decreased cardiac output and decreased peripheral resistance, it is well known that HIRRT may be a consequence of multiple other mechanisms in any given patient [31]. These mechanisms include CRRT-related factors (such as modality, ultrafiltration rate and osmolality shift) and patient-related factors (such as myocardial stunning and autonomic dysfunction) [32]. Taken together, these data challenge the notion that HIRRT is predominantly due to excessive ultrafiltration. Thus, it seems that the assessment of preload-dependence or independence status cannot be easily predicted during a HIRRT episode but requires functional hemodynamic monitoring and continuous cardiac index measurements. Of note, the use of functional hemodynamic in our study was associated with specific therapeutic interventions as a function of preload-dependence status during HIRRT (Fig. 3), suggesting that it may help personalizing CRRT settings as a function of hemodynamic status.

Interestingly, repetitive hemodynamic evaluations during the study (1237 in total) allowed us to identify variables collected before HIRRT onset as independent risk factors for occurrence of HIRRT associated with preload-dependence. Identification of preload-dependence during systematic hemodynamic evaluation before HIRRT onset was a strong predictor of HIRRT associated with preload-dependence. This result is of high importance since contradictory results have been reported about other interventions (sodium profiling, cooler dialysate and UF profiling notably) suggested to prevent HIRRT [33]. Therefore, iterative testing for preload-dependence during CRRT may constitute a useful strategy for guiding net ultrafiltration rate. A higher arterial lactate, a delay since last HIRRT episode below 8 hours, and a lower cardiac output were also associated with higher risk of preload-dependence-related HIRRT. These findings were not unexpected since lower cardiac index is expected in preload dependent patients as a consequence of being in the steep part of the Starling curve [34], arterial lactate is a marker of acute circulatory failure, and lower delay since last HIRRT episode suggests hemodynamic instability. Higher admission SOFA being a protective factor of preload dependence associated HIRRT may be surprising, although it may be a consequence of more aggressive fluid resuscitation in these patients. We are however unable to confirm this hypothesis as the amount of fluid administration was not recorded in the 
present work. Even if they are not sufficient to predict preload-dependency if assessed alone, those parameters could be analyzed as part of a set of variables to adjust net ultrafiltration rate in patients undergoing CRRT. Surprisingly, the net ultrafiltration rate (nor any other CRRT settings) was not identified as an independent risk factor for occurrence of HIRRT associated with preload-dependence in our study.

This study presents several limits. First, the observational feature precludes drawing any causal associations between the independent variables identified by multivariate analysis and HIRRT associated with preload-dependence. Second, like any single-center study, extrapolation of our results to other ICUs may be questionable. Furthermore, the population studied may be highly selected although the main reasons for non-inclusion were lack of PiCCO monitoring and moribund patients. Third, the chosen definition of HIRRT could be debated. Indeed, unlike in the context of end-stage kidney disease on maintenance hemodialysis [35], there is no standardized definition of HIRRT during CRRT in ICU patients $[32,33]$. We used a pragmatic definition, requiring predefined therapeutic interventions in addition to low arterial pressure to qualify HIRRT, similarly to previous studies [36,37]. Four, the study stopped prematurely because enrolment was hindered by nurse staff overwork during the COVID-19 pandemics. Nevertheless, the number of HIRRT largely exceeded the required number computed by power analysis. Finally, hemodynamic data collection and postural tests were realized by ICU nurses, whose expertise in hemodynamic monitoring may be debatable, although regular training session were organized to ensure quality of data acquisition.

Nevertheless, the study has the following strengths. First, the prospective feature of the study ensured a very low rate of missing values, which were nevertheless taken into account during statistical analysis. Second, the high number of HIRRT episodes allowed a high number of risk factors for HIRRT to be selected for inclusion in the multivariate model. Third, preload-dependence was assessed with both PLR in the supine position and the Trendelenburg maneuver in the prone position, i.e. two techniques with very high diagnostic performance to identify preload-dependency $[12,13]$. Furthermore, it has been demonstrated that renal replacement therapy does not alter the measurement of cardiac index by transpulmonary thermodilution and pulse contour analysis [38, 39]. Fourth, although requiring multiple complex hemodynamic evaluations over the first seven days after inclusion, the study demonstrate the feasibility of this monitoring strategy in real-life, without additional nursing staff.

\section{Conclusion}

In this single center study, HIRRT associated with preload-dependence was slightly more frequent than HIRRT without preload-dependence in ICU patients undergoing CRRT. Iterative testing for preloaddependence to adjust fluid removal by CRRT could help prevent HIRRT occurrence during CRRT.

\section{Abbreviations}

$\mathrm{AKI}$

Acute kidney injury 
$\mathrm{Cl}_{95 \%}$

ninety-five percent confidence interval

CRRT

continuous renal replacement therapy

$\mathrm{CVVH}$

continuous veno-venous hemofiltration

CVVHD

continuous veno-venous hemodialysis

HIRRT

hemodynamic instability related to renal replacement therapy

ICU

intensive care unit

OR

odd ratio

PLR

passive leg raising

PPV

pulse pressure variation

SAPS

simplified acute physiology score

Sequential Organ Failure Assessment

SOFA

SVV

stroke volume variation

Declarations

\section{Ethics approval and consent to participate}

The authors state that the study has been approved by a national research ethics committee (CPP Ile de France IV, ID-RCB 2017-A00483-50). Informed consent was obtained from all individual participants included in the study and/or their representative.

\section{Consent for publication}

Not applicable

\section{Availability of data and materials}


The datasets used and/or analyzed during the current study are available from the corresponding author on reasonable request.

\section{Competing interests}

The authors declare that they have no competing interests.

\section{Funding}

Insurance and quality monitoring for the study were funded by Hospices Civils de Lyon.

\section{Authors' contributions}

- GC made substantial contributions to study design, to data acquisition, study analysis, and interpretation of data, AND drafted the manuscript, AND revised the manuscript for important intellectual content, AND approved the version to be published.

- LB made substantial contributions to study design, to data acquisition, study analysis, and interpretation of data, AND revised the manuscript for important intellectual content, AND approved the version to be published.

- MM made substantial contributions to study design, to data acquisition, study analysis, and interpretation of data, AND revised the manuscript for important intellectual content, AND approved the version to be published.

- NC made substantial contributions to data acquisition, and interpretation of data, AND revised the manuscript for important intellectual content, AND approved the version to be published.

- PC made substantial contributions to data acquisition, and interpretation of data, AND revised the manuscript for important intellectual content, AND approved the version to be published.

- LC made substantial contributions to data acquisition, and interpretation of data, AND revised the manuscript for important intellectual content, AND approved the version to be published.

- LF made substantial contributions to data acquisition, and interpretation of data, AND revised the manuscript for important intellectual content, AND approved the version to be published.

- GD made substantial contributions to data acquisition, and interpretation of data, AND revised the manuscript for important intellectual content, AND approved the version to be published.

- JP made substantial contributions to data acquisition, and interpretation of data, AND revised the manuscript for important intellectual content, AND approved the version to be published. 
- HY made substantial contributions to study design, data acquisition, study analysis, and interpretation of data, AND revised the manuscript for important intellectual content, AND approved the version to be published.

- JCR made substantial contributions to study design, to data acquisition, study analysis, and interpretation of data, AND drafted the manuscript, AND approved the version to be published, AND agreed to be accountable for all aspects of the work in ensuring that questions related to the accuracy or integrity of any part of the work are appropriately investigated and resolved.

\section{Acknowledgements}

The authors wish to thank Loredana BABOI for her help with patient screening and data collection, the ICU nurses for their help with hemodynamic data acquisition, and Jeanne Richard for her help with data entry.

\section{References}

1. Hoste EAJ, Bagshaw SM, Bellomo R, Cely CM, Colman R, Cruz DN, et al. Epidemiology of acute kidney injury in critically ill patients: the multinational AKI-EPI study. Intensive Care Med. 2015;41:1411-23.

2. RENAL Replacement Therapy Study Investigators. Bellomo R, Cass A, Cole L, Finfer S, Gallagher M, et al. An observational study fluid balance and patient outcomes in the Randomized Evaluation of Normal vs. Augmented Level of Replacement Therapy trial. Crit Care Med. 2012;40:1753-60.

3. Bouchard J, Soroko SB, Chertow GM, Himmelfarb J, Ikizler TA, Paganini EP, et al. Fluid accumulation, survival and recovery of kidney function in critically ill patients with acute kidney injury. Kidney Int. 2009;76:422-7.

4. Burton JO, Jefferies HJ, Selby NM, McIntyre CW. Hemodialysis-induced cardiac injury: determinants and associated outcomes. Clin J Am Soc Nephrol. 2009;4:914-20.

5. Silversides JA, Pinto R, Kuint R, Wald R, Hladunewich MA, Lapinsky SE, et al. Fluid balance, intradialytic hypotension, and outcomes in critically ill patients undergoing renal replacement therapy: a cohort study. Crit Care. 2014;18:624.

6. Murugan R, Kerti SJ, Chang C-CH, Gallagher M, Clermont G, Palevsky PM, et al. Association of Net Ultrafiltration Rate With Mortality Among Critically III Adults With Acute Kidney Injury Receiving Continuous Venovenous Hemodiafiltration: A Secondary Analysis of the Randomized Evaluation of Normal vs Augmented Level (RENAL) of Renal Replacement Therapy Trial. JAMA Netw Open. 2019;2:e195418.

7. Uchino S, Bellomo R, Morimatsu H, Morgera S, Schetz M, Tan I, et al. Continuous renal replacement therapy: a worldwide practice survey. The beginning and ending supportive therapy for the kidney (B.E.S.T. kidney) investigators. Intensive Care Med. 2007;33:1563-70. 
8. Bagshaw SM, Berthiaume LR, Delaney A, Bellomo R. Continuous versus intermittent renal replacement therapy for critically ill patients with acute kidney injury: a meta-analysis. Crit Care Med. 2008;36:610-7.

9. Akhoundi A, Singh B, Vela M, Chaudhary S, Monaghan M, Wilson GA, et al. Incidence of Adverse Events during Continuous Renal Replacement Therapy. Blood Purif. 2015;39:333-9.

10. Douvris A, Zeid K, Hiremath S, Bagshaw SM, Wald R, Beaubien-Souligny W, et al. Mechanisms for hemodynamic instability related to renal replacement therapy: a narrative review. Intensive Care Med. 2019;45:1333-46.

11. Bitker L, Bayle F, Yonis H, Gobert F, Leray V, Taponnier R, et al. Prevalence and risk factors of hypotension associated with preload-dependence during intermittent hemodialysis in critically ill patients. Crit Care. 2016;20:44.

12. Monnet $X$, Marik $P$, Teboul J-L. Passive leg raising for predicting fluid responsiveness: a systematic review and meta-analysis. Intensive Care Med. 2016;42:1935-47.

13. Yonis H, Bitker L, Aublanc M, Perinel Ragey S, Riad Z, Lissonde F, et al. Change in cardiac output during Trendelenburg maneuver is a reliable predictor of fluid responsiveness in patients with acute respiratory distress syndrome in the prone position under protective ventilation. Crit Care. 2017;21:295.

14. Kidney Disease Outcomes Quality Initiative. KDIGO Clinical practice guidelines for acute kidney injury. Kidney Int Suppl. 2012;2:1-138.

15. Le Gall JR, Lemeshow S, Saulnier F. A new Simplified Acute Physiology Score (SAPS II) based on a European/North American multicenter study. JAMA. 1993;270:2957-63.

16. Vincent JL, Moreno R, Takala J, Willatts S, De Mendonca A, Bruining H, et al. The SOFA (Sepsisrelated Organ Failure Assessment) score to describe organ dysfunction/failure. On behalf of the Working Group on Sepsis-Related Problems of the European Society of Intensive Care Medicine. Intensive Care Med. 1996;22:707-10.

17. Singer M, Deutschman CS, Seymour CW, Shankar-Hari M, Annane D, Bauer M, et al. The Third International Consensus Definitions for Sepsis and Septic Shock (Sepsis-3). JAMA. 2016;315:80110.

18. Monnet X, Teboul J-L. Passive leg raising: five rules, not a drop of fluid! Crit Care Lond Engl. 2015;19:18.

19. R Core Team. R: A language and environment for statistical computing [Internet]. Vienna, Austria: $R$ Foundation for statistical Computing; 2020. Available from: http://www.R-project.org.

20. Bates D, Maechler M, Bolker B, Walker S. Fitting linear mixed-effects models using Ime4. J Stat Softw. 2015;67:1-48.

21. Kuznetsova A, Brockhoff PB, Christensen RHB. LmerTest: Tests in Linear Mixed Effects Models. [Internet]. 2016. Available from: http://CRAN.R-project.org/package=ImerTest.

22. Robin X, Turck N, Hainard A, Tiberti N, Lisacek F, Sanchez J-C, et al. pROC: an open-source package for R and S + to analyze and compare ROC curves. BMC Bioinformatics. 2011;12:77. 
23. Scherer R, PropCls: Various Confidence Interval Methods for Proportions [Internet]. 2018. Available from: https://CRAN.R-project.org/package=PropCls.

24. Villacorta PJ. MultinomialCl: Simultaneous confidence intervals for multinomial proportions according to the method by Sison and Glaz [Internet]. 2012. Available from: https://CRAN.Rproject.org/package=MultinomialCl.

25. van Buuren S, Groothuis-Oudshoom. Mice: multivariate imputation by chained equation in R. J Stat Softw. 2011;45:1-67.

26. Mathews P. Sample size calculations. Practical methods for engineers and scientists. Fairport Harbor: Mathews Malnar and Bailey; 2010.

27. Sison CP, Glaz J. Simultaneous confidence intervals and sample size determination for multinomial proportions. J Am Stat Assoc. 1995;90:366-9.

28. Cavallaro F, Sandroni C, Marano C, La Torre G, Mannocci A, De Waure C, et al. Diagnostic accuracy of passive leg raising for prediction of fluid responsiveness in adults: systematic review and metaanalysis of clinical studies. Intensive Care Med. 2010;36:1475-83.

29. Schortgen F, Soubrier N, Delclaux C, Thuong M, Girou E, Brun-Buisson C, et al. Hemodynamic tolerance of intermittent hemodialysis in critically ill patients: usefulness of practice guidelines. Am J Respir Crit Care Med. 2000;162:197-202.

30. Santiago MJ, López-Herce J, Urbano J, Solana MJ, del Castillo J, Ballestero Y, et al. Complications of continuous renal replacement therapy in critically ill children: a prospective observational evaluation study. Crit Care. 2009;13:R184.

31. Douvris A, Malhi G, Hiremath S, McIntyre L, Silver SA, Bagshaw SM, et al. Interventions to prevent hemodynamic instability during renal replacement therapy in critically ill patients: a systematic review. Crit Care. 2018;22:41.

32. Sharma S, Waikar SS. Intradialytic hypotension in acute kidney injury requiring renal replacement therapy. Semin Dial. 2017;30:553-8.

33. Douvris A, Malhi G, Hiremath S, Mclntyre L, Silver SA, Bagshaw SM, et al. Interventions to prevent hemodynamic instability during renal replacement therapy in critically ill patients: a systematic review. Crit Care Lond Engl. 2018;22:41.

34. Patterson SW, Starling EH. On the mechanical factors which determine the output of the ventricles. J Physiol. 1914;48:357-79.

35. K/DOQI Workgroup. K/DOQI clinical practice guidelines for cardiovascular disease in dialysis patients. Am J Kidney Dis. 2005;45:1-153.

36. Monnet $X$, Cipriani F, Camous $L$, Sentenac $P$, Dres $M$, Krastinova $E$, et al. The passive leg raising test to guide fluid removal in critically ill patients. Ann Intensive Care. 2016;6:46.

37. Du Cheyron D, Terzi N, Seguin A, Valette X, Prevost F, Ramakers M, et al. Use of online blood volume and blood temperature monitoring during haemodialysis in critically ill patients with acute kidney injury: a single-centre randomized controlled trial. Nephrol Dial Transplant. 2013;28:430-7. 
38. Sakka SG, Hanusch T, Thuemer O, Wegscheider K. The influence of venovenous renal replacement therapy on measurements by the transpulmonary thermodilution technique. Anesth Analg. 2007;105:1079-82.

39. Dufour N, Delville M, Teboul J-L, Camous L, Favier du Noyer A, Richard C, et al. Transpulmonary thermodilution measurements are not affected by continuous veno-venous hemofiltration at high blood pump flow. Intensive Care Med. 2012;38:1162-8.

\section{Figures}




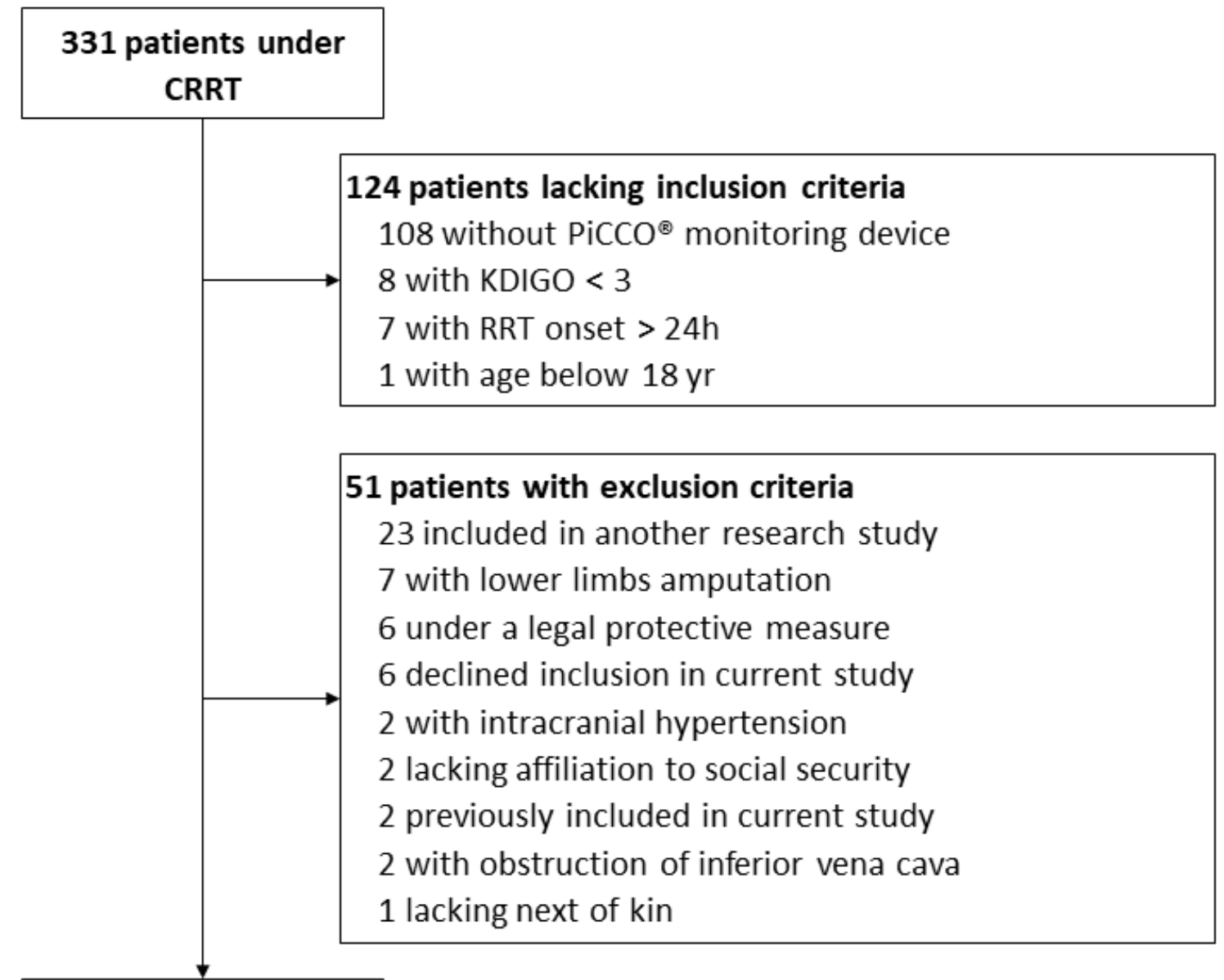

156 patients with eligibility criteria

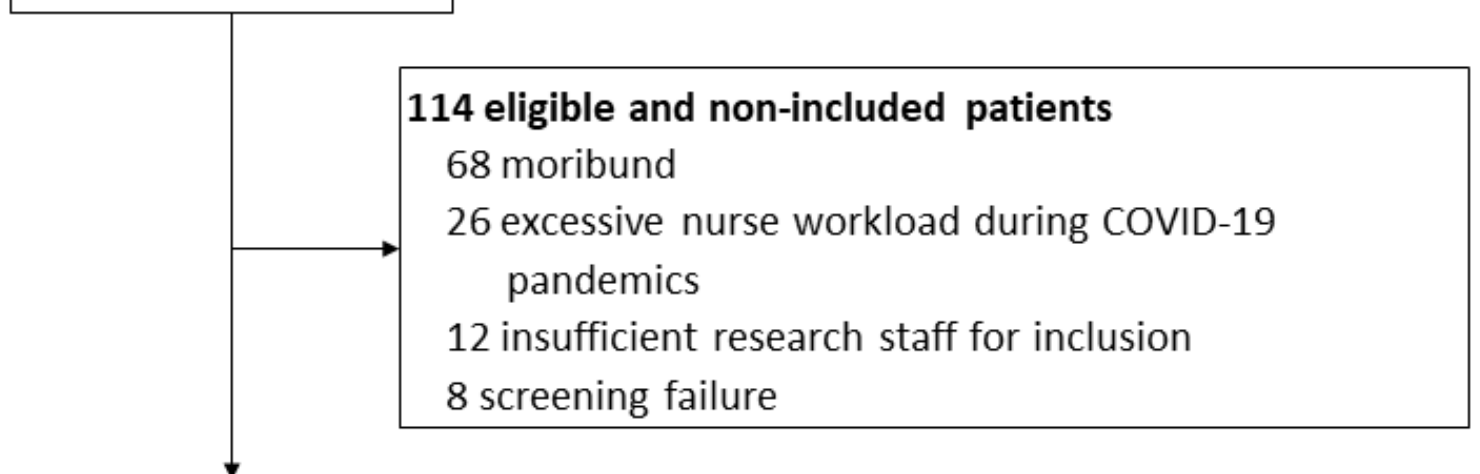

42 patients included

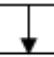

42 patients analyzed

\section{Figure 1}

Study flow chart. CRRT = continuous renal replacement therapy; RRT = renal replacement therapy. 


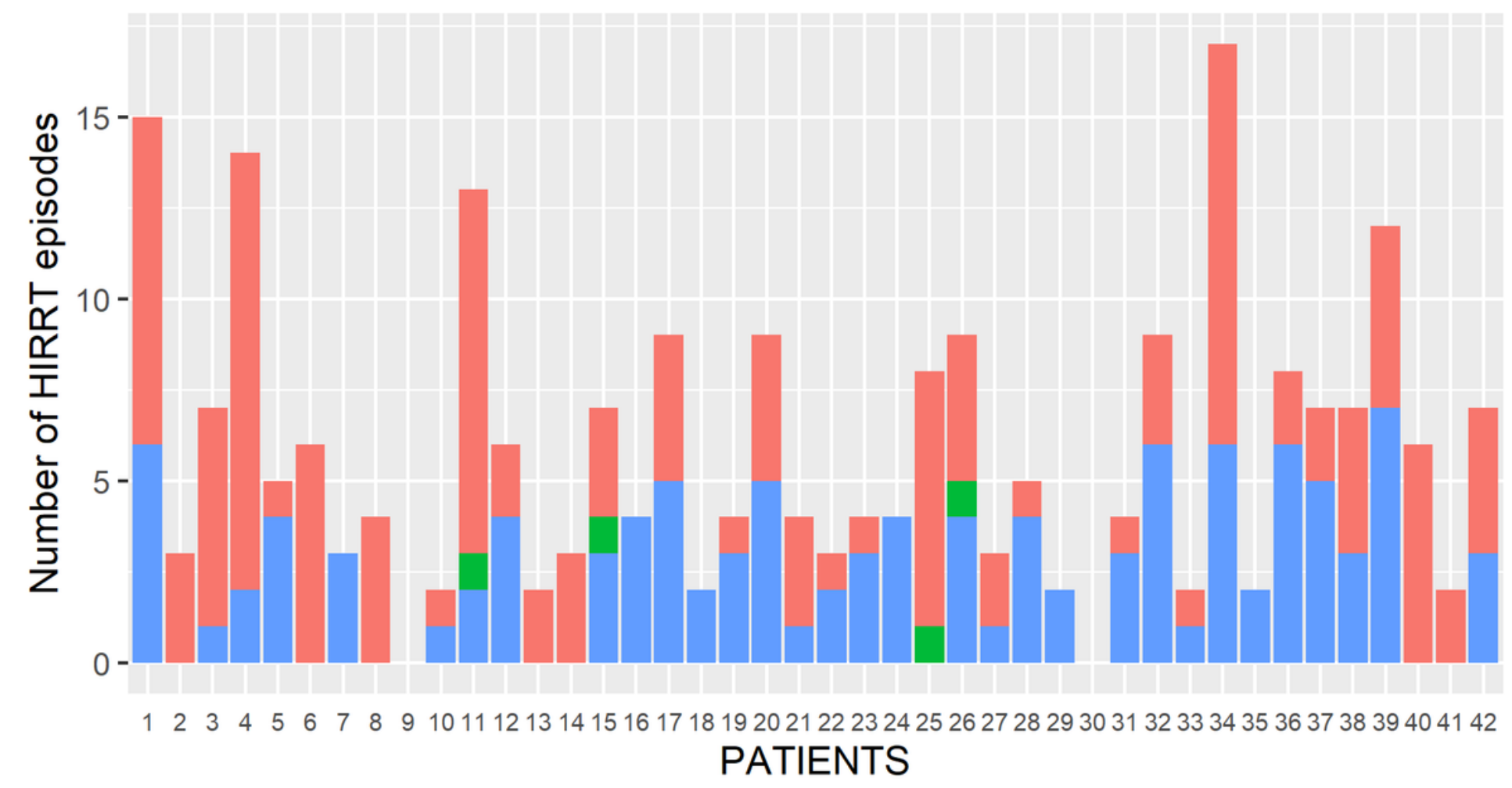

Figure 2

HIRRT episodes as a function of preload dependence status per patient. HIRRT = hemodynamic instability related to renal replacement therapy. 
- HIRRT with preload dependence $\quad$ HIRRT without preload dependence

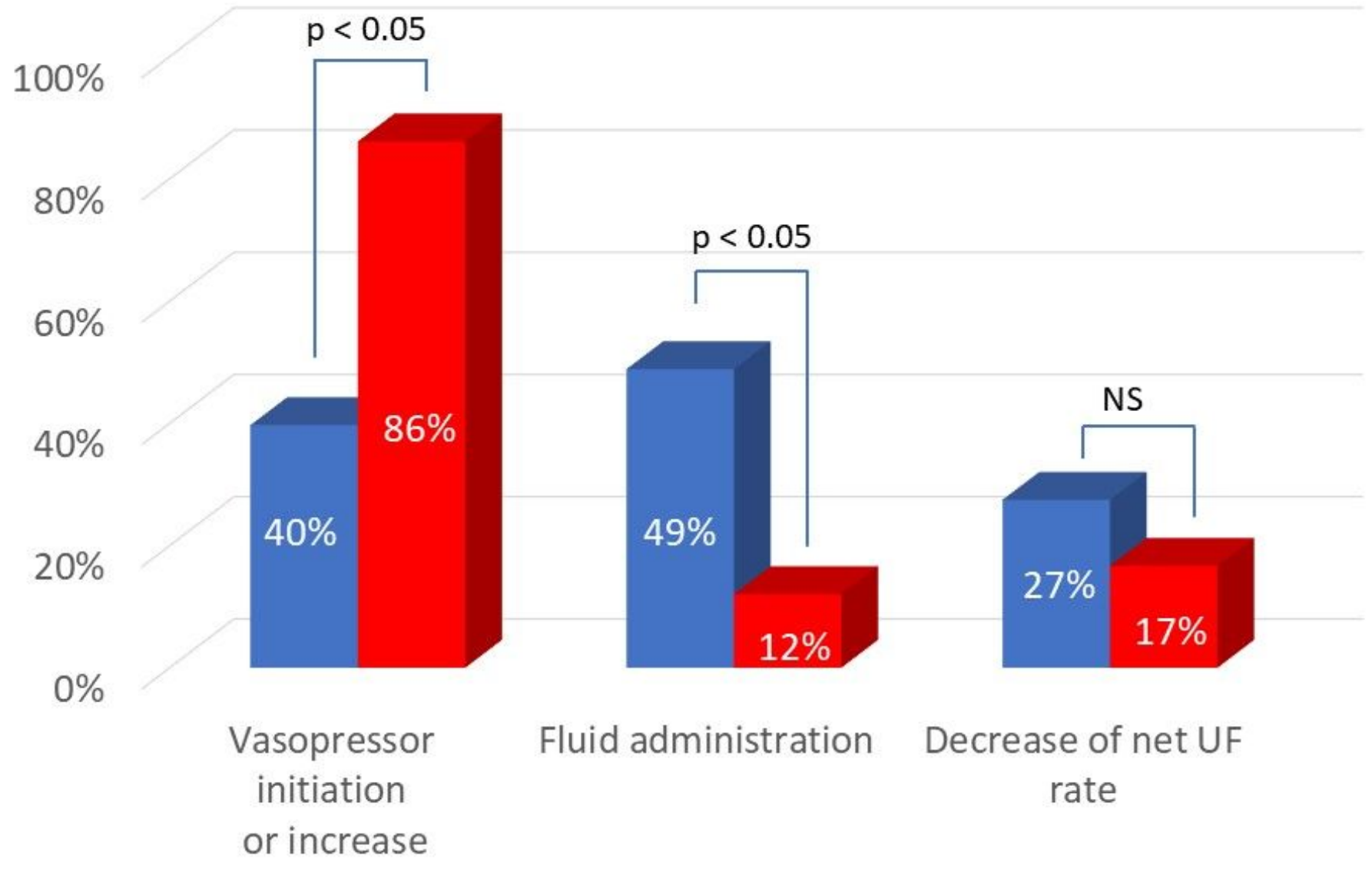

\section{Figure 3}

Therapeutic management of HIRRT. Values per type of HIRRT do not add up to $100 \%$ since multiple interventions could be selected by attending physician. HIRRT = hemodynamic instability related to renal replacement therapy; NS = not significant; UF = ultrafiltration. 


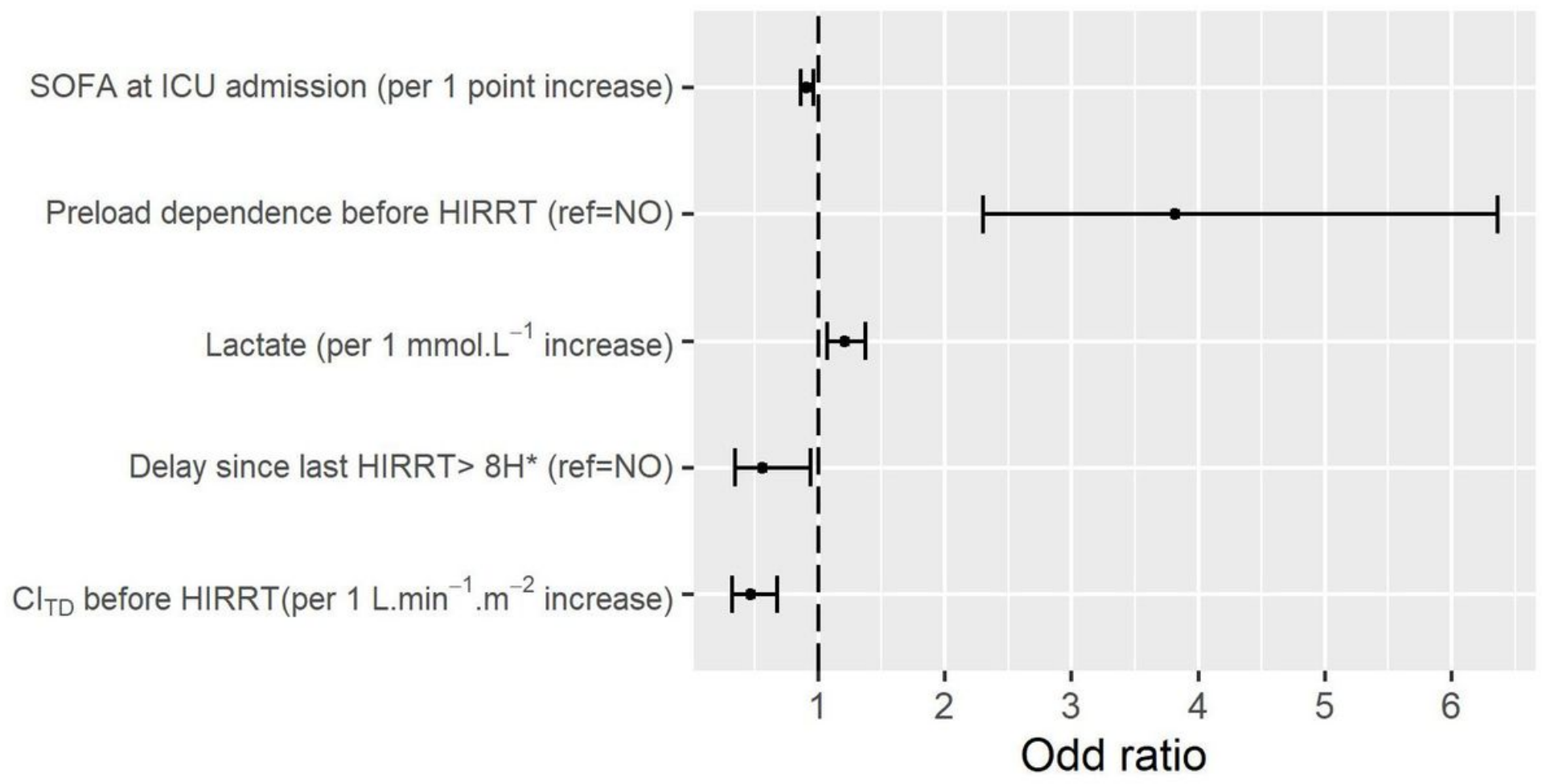

\section{Figure 4}

Forest plot of risk factors for occurrence of HIRRT associated with preload-dependence in multivariate analysis. Bars are $95 \%$ confidence interval of odd ratios. CITD = cardiac index assessed by thermodilution; HIRRT = hemodynamic instability related to renal replacement therapy; ICU = intensive care unit; $\mathrm{OR}$ = odd ratio. * this cut-off value was chosen as it maximized the Youden's index in univariate analysis. The following variables were entered into the multivariate full model: preload-dependence (yes/no), delay since last HIRRT episode > 8 hours (yes/no), delay since CRRT onset, cardiac index assessed by thermodilution, global end-diastolic volume, pulmonary vascular permeability index, pulse pressure variation, systolic arterial pressure, mechanical ventilation status (yes/no), sex male (yes/no), SOFA score at ICU admission, body weight on the day of hemodynamic measurement, SOFA score on the day of hemodynamic measurement; lactate on the day of hemodynamic measurement, base excess on the day of hemodynamic measurement, hemoglobin on the day of hemodynamic measurement, sepsis criteria on the day of hemodynamic measurement (yes/no), septic shock criteria on the day of hemodynamic measurement (yes/no). The following variables were not entered into the multivariate full model because of multicollinearity: cardiac index assessed by pulse contour analysis and global ejection fraction (collinearity with cardiac index assessed by thermodilution), stroke volume variation (collinearity with pulse pressure variation), mean and diastolic arterial pressure (collinearity with systolic arterial pressure), bicarbonate (collinearity with base excess). No significant interaction was identified between any of the selected variables. C-statistic of the final model: 0.77 . Model calibration assessed by the Hosmer -Lemeshow test: $p=0.76$.

\section{Supplementary Files}


This is a list of supplementary files associated with this preprint. Click to download.

- Additionalfile1.docx

- Additionalfile2.docx 